\title{
Administration of Endotoxin, Tumor Necrosis Factor, or Interleukin 1 to Rats Activates Skeletal Muscle Branched-Chain $\alpha$-Keto Acid Dehydrogenase
}

\author{
M. Daud Nawabi, Kevin P. Block, Munna C. Chakrabarti, and Maria G. Buse
}

Departments of Medicine and Biochemistry, Medical University of South Carolina, Charleston, South Carolina 29425

\begin{abstract}
Protein catabolic states (i.e., sepsis and trauma) are thought to be associated with accelerated oxidation of branched-chain amino acids (BCAA). Branched-chain $\alpha$-keto acid dehydrogenase (BCKAD), the rate-limiting enzyme for BCAA oxidation by muscle, is regulated by phosphorylation/dephosphorylation. Skeletal muscle BCKAD was only $2-4 \%$ active in control rats. Intravenous injection of Salmonella enteritidis endotoxin (0.25-10 $\mathrm{mg} / \mathrm{kg})$ did not change total BCKAD activity, but increased the percent active enzyme in muscle three- to fourfold in 4-6 h. Identical results were observed in adrenalectomized rats pretreated with one dose of $\alpha$-methylprednisolone (2.5 $\mathrm{mg} / \mathrm{kg}$ i.p.) 30-60 min before saline or endotoxin injection, indicating that endotoxin's effect was not mediated by hypersecretion of adrenal hormones. Cortisone pretreatment of normal rats $(100 \mathrm{mg} / \mathrm{kg}$ per d) for $2 \mathrm{~d}$ prevented endotoxin-induced activation of muscle BCKAD, suggesting that endogenous secretion products mediated BCKAD activation by endotoxin. Human recombinant tumor necrosis factor- $\alpha$ and/or IL-1 $\beta$ or $\alpha(50 \mu \mathrm{g} / \mathrm{kg})$ increased muscle BCKAD activation two- to fourfold in normal rats 4-6 $\mathrm{h}$ after intravenous injection. We conclude that cytokine-mediated activation of muscle BCKAD may contribute to accelerated BCAA oxidation in septicemia. (J. Clin. Invest. 1990. 85:256-263.) branchedchain $\alpha$-keto acid dehydrogenase $\bullet$ endotoxin $\bullet$ enzyme activation • interleukin-1 • skeletal muscle • tumor necrosis factor
\end{abstract}

\section{Introduction}

Septic shock is one of the most common problems encountered in surgical intensive care units (1). Septicemia is characterized by severe muscle wasting with the majority of amino acids being released from skeletal muscle for eventual uptake by the liver for glucogenesis (2) and synthesis of acute phase plasma proteins $(3,4)$. The ability of muscle to utilize glucose, fat, and ketones as energy sources is compromised during septic shock (5-10). However, total body leucine oxidation was increased by $\sim 50 \%$ in rats with Pseudomonas aeruginosa bacteremia (11).

A portion of this work was presented at the Annual Meeting of the Association of American Physicians, 2 May 1988, and was published in abstract form 1988. (Clin. Res. 36:623a.)

Address reprint requests to Dr. Buse, Department of Medicine, Medical University of South Carolina, 171 Ashley Avenue, Charleston, SC 29425.

Received for publication 9 December 1988 and in revised form 12 September 1989.

J. Clin. Invest.

(c) The American Society for Clinical Investigation, Inc

0021-9738/90/01/0256/08 \$2.00

Volume 85, January 1990, 256-263
Woolf and co-workers $(12,13)$ studied femoral arteriovenous amino and keto acid differences in dogs treated with Escherichia coli endotoxin and concluded that branchedchain amino acids (BCAA) ${ }^{1}$ were actively taken up and oxidized by muscle during sepsis. Similar findings were reported in studies of septic patients (14). Oxidation of medium L-[1$\left.{ }^{14} \mathrm{C}\right]$ leucine by isolated muscles from septic man (3) and rabbit (15) was shown to be increased. The mechanism responsible for the apparent increase in BCAA catabolism is not known.

The rate-limiting enzyme for BCAA metabolism in skeletal muscle is branched-chain $\alpha$-keto acid dehydrogenase (BCKAD), an enzyme related both structurally and functionally to the pyruvate dehydrogenase complex $(16,17)$. BCKAD is controlled by a phosphorylation (inactivation)-dephosphorylation (activation) mechanism catalyzed by an intrinsic kinase and phosphatase $(16,17)$. As of this writing, no reports of septicemia's effect on BCKAD activity have appeared in the literature. In contrast, septicemia has been shown to decrease the activation state of the pyruvate dehydrogenase complex in skeletal muscle (18). BCKAD activity is normally very low in muscle and has proved difficult to quantitate. Recently, we have shown that the complex is activated rapidly after leucine infusion (19), glucocorticoid treatment (20), or ingestion of a protein meal (21).

Administration of bacterial endotoxin elicits the systemic manifestations observed in animals with gram hegative septicemia (i.e., fever, hypotension, shock, tissue injury). There is increasing evidence that these changes are not direct effects of endotoxin, but are mediated by potent cytokines released by macrophages and probably other cells, in response to stimulation by bacterial endotoxin (reviewed in 22). Foremost among these are tumor necrosis factor- $\alpha$ (TNF, cachectin) and IL- $1 \beta$, which are now available in recombinant form. While both IL-1 and TNF can mimic many of the systemic effects of endotoxin, TNF may be the major cytokine released by endotoxin activated macrophages $(23,24)$. Indeed, endotoxin-induced shock and death has been prevented by administering antibodies to TNF to experimental animals before endotoxin administration $(25,26)$. IL-1 $(27,28)$ and TNF (29-32) have been implicated as causative agents of accelerated muscle protein catabolism in conditions such as sepsis and cachexia; other studies suggest that neither agent induces muscle protein degradation, which may be caused by a yet unidentified cytokine (33-36).

In this study we administered endotoxin or cytokines to rats to assess their effect on the activation state of muscle BCKAD. Our data indicate that intravenous endotoxin administration results in activation of muscle BCKAD within 4

1. Abbreviations used in this paper: Adx, adrenalectomized; BCAA, branched-chain amino acids; BCKAD, branched-chain $\alpha$-keto acid dehydrogenase; KIC, $\alpha$-keto isocaproic acid; LPS, lipopolysaccharide; MP, 6- $\alpha$-methylprednisolone; TNF, tumor necrosis factor- $\alpha$. 
h; the effect is not mediated by stimulated glucocorticoid secretion. Furthermore, injection of TNF or IL-1 $\beta$ or $\alpha$ cause similar BCKAD activation in muscle.

\section{Methods}

Animals. Male Wistar (WI) BR rats (Charles River Laboratories, Wilmington, MA), weighing 150-250 g, were fed a common rodent chow containing 27\% mixed protein (Wayne Rodent Blox; Continental Grain, Chicago, IL) and water ad lib. throughout the study. Rats fed this diet consume $\sim 15 \mathrm{~g}$ of feed per $\mathrm{d}$ and grow $6 \mathrm{~g} / \mathrm{d}$. $2 \mathrm{~d}$ of cortisone treatment (see dose below) does not alter food intake (20). Food was withdrawn 1-2 h before injections of endotoxin, cytokine, or saline. Rats were kept on a 12-h-12 h light-dark cycle in a room maintained at $26^{\circ} \mathrm{C}$. Rats were anesthetized with methoxyflurane (Metofane; Pitman-Moore, Washington Crossing, NJ) during intravenous injections and all surgical procedures.

\section{Treatments}

Endotoxin administration. The effects of endotoxemia on muscle BCKAD were investigated in rats administered lipopolysaccharide B Salmonella enteritidis endotoxin (Difco Laboratories, Detroit, MI) via tail vein. Endotoxin diluted in $0.9 \%(\mathrm{wt} / \mathrm{vol})$ saline was given in doses ranging from 0.25 to $10 \mathrm{mg} / \mathrm{kg}$ body wt. Control rats received an equal volume of $0.9 \%(\mathrm{wt} / \mathrm{vol})$ saline.

In one study rats were pretreated with glucocorticoids before endotoxin administration. Cortisone acetate $(100 \mathrm{mg} / \mathrm{kg}$; General Injectables and Vaccines, Bastian, VA) or saline was administered subcutaneously, daily at 5 p.m. for $2 \mathrm{~d}$ and once again $1 \mathrm{~h}$ before intravenous endotoxin $(10 \mathrm{mg} / \mathrm{kg})$ administration. On the morning of the endotoxin treatment, cortisone and saline groups were divided as follows (subcutaneous injection-intravenous injection): (a) Saline-saline; $(b)$ saline-endotoxin; (c) cortisone-saline; $(d)$ cortisone-endotoxin.

In some studies rats underwent bilateral adrenalectomy (Adx) 5-7 d before endotoxin treatment and were provided with a $1 \% \mathrm{NaCl}$ solution as well as drinking water to maintain salt balance. Controls underwent sham operations. In preliminary studies, administration of endotoxin $(10 \mathrm{mg} / \mathrm{kg})$ to Adx rats resulted in $100 \%$ mortality $3 \mathrm{~h}$ postinjection. Therefore, a replacement dose of 6- $\alpha$-methylprednisolone $(2.5 \mathrm{mg} / \mathrm{kg}$ ) (MP; Elkins-Sinn, Inc., Cherry Hill, NJ) or saline was administered intraperitoneally $30-60 \mathrm{~min}$ before intravenous endotoxin or saline treatment. Four groups of rats were studied in parallel (Adx/control-intraperitoneal injection-intravenous injection): (a) control-MP-saline; (b) Adx-saline-saline; (c) Adx-MP-saline; (d) Adx-MPendotoxin. In the glucocorticoid and Adx studies, rats were killed and samples for muscle BCKAD and blood and muscle BCAA measurements were taken $6 \mathrm{~h}$ after intravenous administration of endotoxin or saline.

Cytokines. Human recombinant TNF $\left(9.6 \times 10^{6} \mathrm{U} / \mathrm{mg}\right)$, IL-1 $\beta(5$ $\left.\times 10^{7} \mathrm{U} / \mathrm{mg}\right)$ and IL-1 $\alpha\left(0.94 \times 10^{7} \mathrm{U} / \mathrm{mg}\right)$, gifts from Biogen Research Corp. (Cambridge, MA) were prepared in PBS containing $1 \mathrm{mg} / \mathrm{ml}$ BSA and administered intravenously to intact rats. Controls received intravenous injections of equal volumes of PBS containing albumin. Preparations of TNF and IL-1 contained $<0.12 \mathrm{ng} / \mathrm{ml}$ of endotoxin.

Cytokines were administered as a single bolus at doses ranging between 10 and $100 \mu \mathrm{g} / \mathrm{kg}$ i.v. TNF doses were calculated to yield maximal plasma concentrations similar to the peak TNF concentration measured in rabbit plasma $\left(\sim 2.5 \times 10^{3} \mathrm{U} / \mathrm{ml}\right)$ after injections of highly purified lipopolysaccharide (LPS) (26). Assuming distribution in the extracellular space of $\sim 25 \%$ of body wt the maximal concentration of TNF that could have reached muscle cells after bolus of 50 $\mu \mathrm{g} / \mathrm{kg}$ i.v. $\left(5 \times 10^{5} \mathrm{U} / \mathrm{kg}\right)$ would be $2 \times 10^{3} \mathrm{U} \mathrm{ml}$.

$B C K A D$ assay. The method for determining BCKAD activity and activation state in muscle has been described in detail previously (19, 20). Briefly, hindlimb muscles were frozen in situ with Wollenberger tongs precooled in liquid nitrogen. BCKAD was extracted from powdered frozen muscle in the presence of protease, phosphatase, and kinase inhibitors and then precipitated with polyethylene glycol. Basal (in vivo) BCKAD activities were determined immediately after redissolving the precipitated proteins, and total (fully active) enzyme activities were measured after preincubation of the extract at $37^{\circ} \mathrm{C}$ with 15 $\mathrm{mM} \mathrm{Mg}^{2+}$ before assay. BCKAD was quantitated by ${ }^{14} \mathrm{CO}_{2}$ release from $0.1 \mathrm{mM} \alpha$-keto $\left[1-{ }^{14} \mathrm{C}\right]$ isocaproate at $37^{\circ} \mathrm{C}$. Mean total activities measured in different studies ranged from 32 to $48 \mathrm{nmol} \cdot \mathrm{min}^{-1} \cdot \mathrm{g}$ muscle ${ }^{-1}$, with an overall mean for all observations $(n=219)$ of 37.1 \pm 2.5 . No significant differences in total BCKAD activities were observed in response to any of the experimental manipulations, therefore results are presented as percentage of BCKAD in the active form, calculated as (basal activity/total activity) $\times 100$.

Other analyses. Amino acid concentrations in plasma and muscle extracts were measured as described previously (37). Plasma corticosterone concentrations were measured by RIA using antiserum B3-163 from Endocrine Sciences (Tarzana, CA) according to instructions supplied by the manufacturer.

Statistical analyses of differences between groups were performed by Student's $t$ test (38) and by analysis of variance followed by a multiple comparison test (Peritz $F$ test [39]) as appropriate. Values for percent active complex were subjected to square root transformation before statistical analysis as percentages are distributed binomially rather than normally (38). Simple linear correlations were determined by standard methods (38). All values shown are means \pm SEM.

\section{Results}

Effects of endotoxin. As reported previously, in saline injected rats (19-21), the activation state of skeletal muscle BCKAD was very low (only $2-4 \%$ active). Intravenous injection of endotoxin $(10 \mathrm{mg} / \mathrm{kg})$ caused time-dependent activation of the complex (Fig. 1). While the mild increase in activity observed $2 \mathrm{~h}$ after injection was not significant, muscle BCKAD activity was increased three- to fivefold over basal levels $(P<0.01)$ 4-8 $h$ after endotoxin administration. This increase represented activation of the enzyme complex, since total enzyme activity was unchanged at all time points $(48 \pm 3 \mathrm{nmol} / \mathrm{min}$ per $\mathrm{g}$; $n$

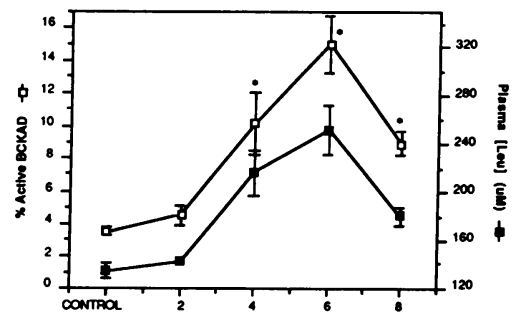

Figure 1. Time course of muscle BCKAD activation, circulating leucine and corticosterone concentrations after endotoxin administration. Salmonella enteritidis endotoxin $(10 \mathrm{mg} / \mathrm{kg})$ was administered intravenously and rats killed

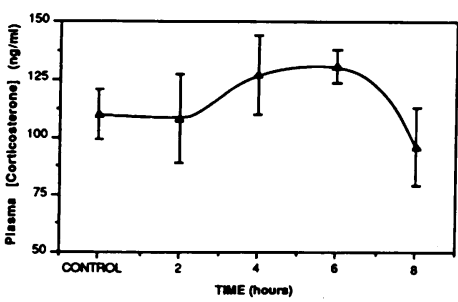
$2,4,6$, and 8 h postinjection. Control rats received equal volumes of saline. Muscle BCKAD activity was measured as described in Methods and the percent active complex computed as basal (in vivo) activity divided by total (fully active) activity $\times 100$. Plasma leucine and corticosterone concentrations were measured as described in Methods. Values are means \pm SEM for three rats/group for the 2- and 8-h time points; the 4-h time point $(n=9)$ represents pooled data from time course and dose response studies (Fig. 2) and the 6-h time point ( $n=$ 10) represents pooled data from time course studies and endotoxin treated controls in Fig. 3. Controls $(n=16)$ are pooled from the three studies. ${ }^{*} P<0.01$ compared with control values. 
=38). Maximal BCKAD activation was observed $6 \mathrm{~h}$ after endotoxin injection, it decreased by $8 \mathrm{~h}$, although it was still significantly above control levels $(P<0.01)$. Controls were killed at various time intervals after saline injection; as previously reported (20) BCKAD activity was unchanged and not distinguishable from uninjected controls.

The transamination product of leucine, $\alpha$-ketoisocaproate (KIC) is a potent inhibitor of BCKAD kinase $(16,17)$. For the reason that endotoxin increases net protein catabolism in muscle (40), it seemed possible that the activation of the complex after endotoxin administration resulted from increased availability of intracellular leucine and KIC which would be reflected in changes in circulating leucine concentrations. As shown in Fig. 1, plasma leucine increased from 130 to $240 \mu \mathrm{M}$ $6 \mathrm{~h}$ after endotoxin, and the changes in circulating leucine paralleled those of BCKAD activity $(r=0.69 ; P<0.01 ; n$ $=38$ ). Plasma isoleucine, valine, and phenylalanine concentrations increased in parallel with circulating leucine (data not shown).

We reported previously that increased circulating glucocorticoids result in activation of muscle $\mathrm{BCKAD}$, although the magnitude of activation observed (20) was less than that after endotoxin injection (Fig. 1). Since endotoxin injection may stimulate glucocorticoid secretion, corticosterone in plasma was measured in the time course study. No statistically significant change in circulating corticosterone concentrations was observed after endotoxin administration (Fig. 1).

An endotoxin dose response is shown in Fig. 2. BCKAD activity was significantly increased $(\sim 50 \%$ activation above control) $4 \mathrm{~h}$ after the injection of $0.25 \mathrm{mg} / \mathrm{kg}$ endotoxin $(P$ $<0.01$ ). Maximal activation (approximately three to four times baseline) was observed $4 \mathrm{~h}$ after injecting $1 \mathrm{mg} / \mathrm{kg}$ endotoxin with higher doses causing no further activation. It is noteworthy that, while endotoxin doses between 1 and 10 $\mathrm{mg} / \mathrm{kg}$ significantly increased circulating leucine $(\sim 80 \%$ increase, Fig. $2, P<0.05), 0.25 \mathrm{mg} / \mathrm{kg}$ endotoxin activated BCKAD without a detectable increase in circulating leucine. Plasma levels of the other BCAA and phenylalanine paralleled those of leucine (see Table I for representative measurements).

Pretreatment with glucocorticoids elicits resistance to endotoxin and in vitro exposure of peritoneal macrophages to glucocorticoids before endotoxin challenge prevents TNF production in response to endotoxin at a transcriptional and posttranscriptional step (41). We tested the effect of pretreating rats for $2 \mathrm{~d}$ with cortisone $(100 \mathrm{mg} / \mathrm{kg}$ per $\mathrm{d})$ on endotoxin

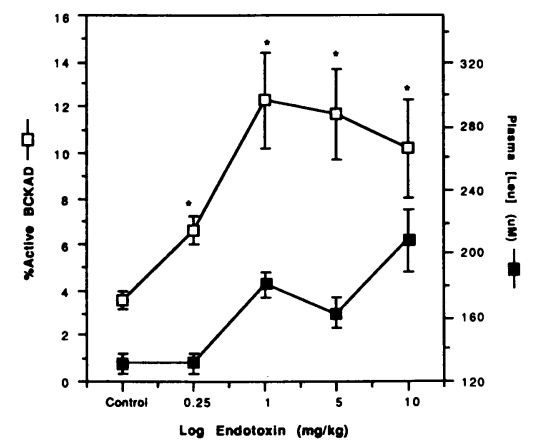

Figure 2. Effect of increasing doses of endotoxin on percentage of active BCKAD and plasma concentrations of leucine. Rats were injected with $0,25,1,5$, and $10 \mathrm{mg} / \mathrm{kg}$ endotoxin i.v. and killed $4 \mathrm{~h}$ postinjection. Muscle BCKAD activity and plasma leucine concentrations were measured

as in Fig. 1. Values are means \pm SEM for five to eight rats per group, except for the 10-mg dose $(n=9)$ and controls $(n=12)$, which represent pooled data from time course (Fig. 1) and dose response experiments. ${ }^{*} P<0.01$ compared with control values.
Table I. Effects of Endotoxin, TNF and IL-1 Administration on Circulating BCAA and Phenylalanine Concentrations in the Rat

\begin{tabular}{|c|c|c|c|c|c|}
\hline \multirow[b]{2}{*}{ Group } & \multirow[b]{2}{*}{$n$} & \multicolumn{4}{|c|}{ Plasma amino acid concentration } \\
\hline & & Leu & Ile & Val & Phe \\
\hline & & \multicolumn{4}{|c|}{$n m o l / m l$} \\
\hline Control* & 38 & $140 \pm 5$ & $84 \pm 3$ & $207 \pm 10$ & $63 \pm 2$ \\
\hline \multicolumn{6}{|l|}{ Endotoxin } \\
\hline$(0.25 \mathrm{mg} / \mathrm{kg})$ & 6 & $124 \pm 9$ & $69 \pm 7$ & $175 \pm 10^{\ddagger}$ & $65 \pm 2$ \\
\hline Endotoxin $(10 \mathrm{mg} / \mathrm{kg})$ & 9 & $209 \pm 20^{\ddagger}$ & $110 \pm 11^{\ddagger}$ & $291 \pm 32^{\ddagger}$ & $101 \pm 17^{\ddagger}$ \\
\hline $\mathrm{IL}-1 \beta(50 \mu \mathrm{g} / \mathrm{kg})$ & 6 & $147 \pm 10$ & $86 \pm 10$ & $218 \pm 29$ & $67 \pm 1$ \\
\hline TNF $(50 \mu \mathrm{g} / \mathrm{kg})$ & 6 & $127 \pm 6$ & $77 \pm 3$ & $179 \pm 10$ & $58 \pm 3$ \\
\hline
\end{tabular}

* Control values were pooled from the relevant studies. All rats were killed $4 \mathrm{~h}$ after injection. Plasma amino acid concentrations were determined as described in Methods. Values are means \pm SEM for number of rats given.

${ }^{\ddagger} P<0.05$ compared with control values.

induced muscle BCKAD activation. As reported previously (20) glucocorticoid treatment caused significant (approximately two times, $P<0.05$ ) activation of BCKAD (Fig. 3). The dose of cortisone acetate used suppressed endogenous plasma corticosterone to undetectable levels in saline injected rats, although after endotoxin challenge plasma corticosterone increased significantly $(P<0.01)$ in cortisone-suppressed rats. Also, endotoxin administration resulted in a significant $(P$ $<0.05)$ although modest $(\sim 20 \%)$ increase in plasma corticosterone when given to normal rats. Endotoxin treatment of saline-pretreated controls activated muscle BCKAD approximately fourfold; this effect was significantly greater than the activation observed with glucocorticoid treatment alone $(P$ $<0.01$ ). Injection of endotoxin into glucocorticoid treated rats caused no greater activation than that observed with cortisone treatment alone, indicating that cortisone treatment prevented endotoxin induced BCKAD activation. Circulating plasma

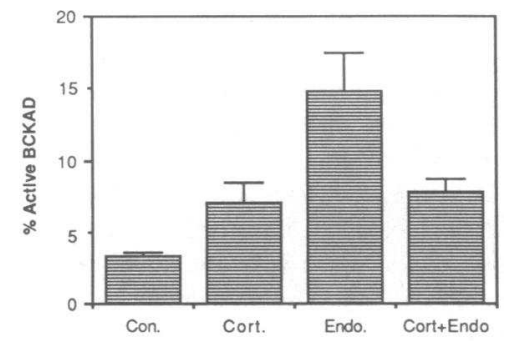

Figure 3. Effect of glucocorticoid pretreatment on endotoxin-mediated activation of muscle BCKAD. Rats were injected daily for 2 $\mathrm{d}$ and on the morning of the experiment with cortisone acetate (Cort., $100 \mathrm{mg} / \mathrm{kg} \mathrm{s.c.)}$. Control rats (Con.) received an equal volume of saline. On the day of the experiment rats were injected with $10 \mathrm{mg} / \mathrm{kg}$ endotoxin (Endo) or saline i.v. and killed $6 \mathrm{~h}$ later. Muscle BCKAD activity, plasma leucine and corticosterone concentrations were measured as in Fig. 1. Values are means \pm SEM for six to eight rats per group. 
leucine (Fig. 3), the other BCAA, and phenylalanine (data not shown) also failed to increase in glucocorticoid-treated rats after endotoxin injection.

To further rule out the possibility that endotoxin-induced activation of muscle BCKAD was mediated by endogenous adrenal secretion products, the effects of endotoxin were studied in rats $5 \mathrm{~d}$ after adrenalectomy. Because in preliminary experiments all adrenalectomized rats died within $4 \mathrm{~h}$ after endotoxin injection, the experimental design was modified to include a single injection of $\alpha$-methylprednisolone (MP, 2.5 $\mathrm{mg} / \mathrm{kg}$ i.p.) $30-60 \mathrm{~min}$ before the injection of endotoxin (10 $\mathrm{mg} / \mathrm{kg}$ i.v.) (Fig. 4). With this experimental design, endotoxin caused no mortality in adrenalectomized rats within $6 \mathrm{~h}$. Adrenalectomy alone did not affect the activation state of muscle BCKAD, and the injection of a small dose of MP caused only minimal activation of the complex $(\sim 30 \%$ above baseline, $P$ $<0.01)$ in both control and in adrenalectomized rats. As in control rats, administration of endotoxin to adrenalectomized MP-treated rats caused fourfold activation of muscle BCKAD activity in $6 \mathrm{~h}(P<0.01)$. Fig. 4 also demonstrates that adrenalectomized rats had undetectable levels of corticosterone in plasma, and that plasma leucine increased after endotoxin treatment in adrenalectomized-MP treated rats $(P<0.01)$ to the same degree as in intact rats treated with endotoxin. These results rule out the possibility that endotoxin-induced muscle BCKAD activation is mediated by adrenal secretion products, although a permissive role for glucocorticoids cannot be dismissed.

Effects of IL-1 and TNF. Endotoxin is known to stimulate secretion of cytokines by macrophages and the studies in Fig. 3 suggested that the effect of endotoxin on BCKAD activation may be mediated by endogenously secreted cytokines. Since IL-1 and TNF are major products of activated macrophages, and are known to mimic some of the effects of endotoxin, their
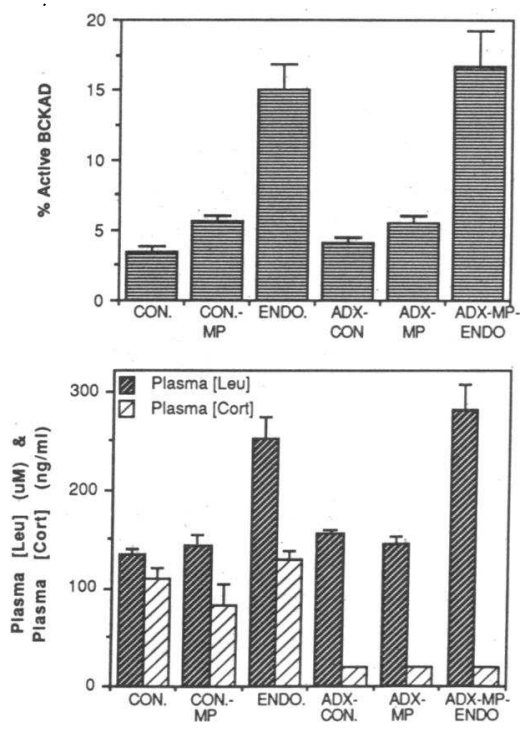

Figure 4. Effect of endotoxin administration on muscle BCKAD, plasma leucine and corticosterone concentrations in adrenalectomized rats. Rats were adrenalectomized (ADX) $5 \mathrm{~d}$ before experiments. A single maintenance dose of $\alpha$ methylprednisolone (MP; $2.5 \mathrm{mg} / \mathrm{kg}$ i.p.) was administered $30-60$ min before endotoxin (ENDO, $10 \mathrm{mg} / \mathrm{kg}$ i.v.) to avoid high rates of mortality. Rats were killed 6 hours after endotoxin or saline administration. Muscle BCKAD activity,

plasma leucine and corticosterone concentrations were measured as in Fig. 1. Values are means \pm SEM. CON - MP, intact MP pretreated rats $(n=4)$; ADX-CON, ADX rats injected with saline $(n=5)$; ADX-MP, ADX rats treated with MP followed by saline $(n=6)$; ADX-MP-ENDO $=$ ADX rats treated with MP followed by endotoxin $(n=7)$. Intact controls treated with saline $(\mathrm{CON}, n, 16)$ or with endotoxin (ENDO, $n, 10)$ are shown for comparison and are from Fig. 1. effects on muscle BCKAD activity were tested. The time course of activation of muscle BCKAD after injection of 50 $\mu \mathrm{g} / \mathrm{kg}$ i.v. IL- $\beta$ to intact (nonadrenalectomized) rats is shown in Fig. 5. The activation state of BCKAD was unaltered at $2 \mathrm{~h}$ and increased about fourfold $4 \mathrm{~h}$ after IL-1 $\beta$ administration. Activation of BCKAD at $6 \mathrm{~h}$ was slightly less than at $4 \mathrm{~h}$, but was still more than threefold above control. At no time point after IL- $1 \beta$ injection was there a detectable change in the concentrations of circulating leucine (Fig. 6), or in the concentrations of the other BCAA or phenylalanine (Table I). Injection of $100 \mu \mathrm{g} / \mathrm{kg} \mathrm{IL-1} \beta$ caused no greater activation of BCKAD $6 \mathrm{~h}$ after injection $(10.6 \pm 1.1 \%, n=6)$ then $50 \mu \mathrm{g} / \mathrm{kg}(10.2 \pm 0.9 \%, n$ $=10)$. IL- $\alpha(50$ or $100 \mu \mathrm{g} / \mathrm{kg})$ caused approximately twofold activation of BCKAD $4 \mathrm{~h}$ after injection (control $=2.9 \pm 0.2 \%$; IL- $1 \alpha=5.4 \pm 0.4 \%$ and $5.8 \pm 1.1$ for 50 and $100 \mu \mathrm{g} / \mathrm{kg}$, respectively; $n=3-4$ /group).

The time course for activation of muscle BCKAD after injection of $50 \mu \mathrm{g} / \mathrm{kg}$ i.v. TNF to intact rats is shown in Fig. 6 $A$. Unlike the results obtained with endotoxin and IL-1 $\beta$, muscle BCKAD was activated as early as $2 \mathrm{~h}$ after TNF administration. Maximal enzyme activation was observed $4 \mathrm{~h}$ after TNF injection and returned towards control values by $6 \mathrm{~h}$. Circulating leucine concentrations were not significantly altered by TNF treatment (Fig. $6 \mathrm{~A}$ ). A dose response to TNF obtained $4 \mathrm{~h}$ after intravenous injection to intact rats is shown in Fig. $6 \mathrm{~B}$. At a dose of $10 \mu \mathrm{g} / \mathrm{kg}$ TNF we observed a small but significant activation of muscle BCKAD, while approximately threefold activation was observed after the injection of 50 or $100 \mu \mathrm{g} / \mathrm{kg}$. While $100 \mu \mathrm{g} / \mathrm{kg}$ TNF caused slightly greater activation than $50 \mu \mathrm{g} / \mathrm{kg}$, the difference was not statistically significant $(P>0.05<0.1)$. As with IL-1, TNF administration caused no change in circulating levels of leucine, other BCAA or phenylalanine (Table I).

Because IL-1 and TNF act via separate receptors (22), we examined the possible additive effects of cytokines on muscle BCKAD activity. Administration of $100 \mu \mathrm{g} / \mathrm{kg}$ of IL- $1 \beta$ or TNF separately caused no clinically evident ill effects while when given together they caused $100 \%$ mortality at $6 \mathrm{~h}$ and $50 \%$ at $4 \mathrm{~h}$. ( $n=4-6 /$ group). Administration of $50 \mu \mathrm{g} / \mathrm{kg}$ of IL- $1 \beta$ and TNF together caused no mortality and resulted in $8.9 \pm 0.8 \%$ BCKAD activation after $6 \mathrm{~h}(n=4)$, which is similar to the activity observed after administering IL-1 $\beta$ alone (Fig. 5).

Since it was surprising that cytokine treatment resulted in muscle BCKAD activation without a concomitant rise in circulating leucine, in some experiments the concentrations of BCAA and phenylalanine were also measured in muscle, $4 \mathrm{~h}$

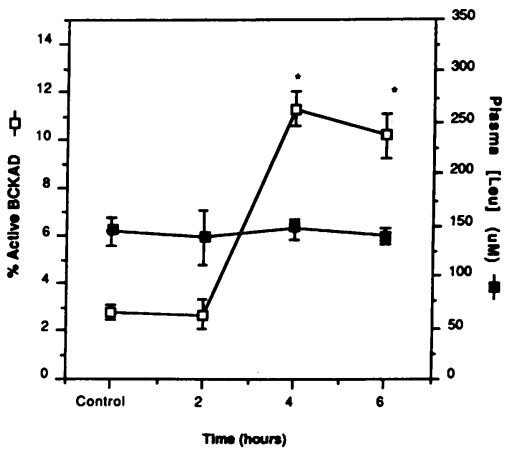

Figure 5. Time course of muscle BCKAD activation and circulating leucine concentrations after Interleukin- $1 \beta$ administration. IL-1 (50 $\mu \mathrm{g} / \mathrm{kg}$ i.v.) was administered and rats were killed 2, 4, and $6 \mathrm{~h}$ later. Controls received equal volumes of PBS containing albumin. Muscle BCKAD activity and plasma leucine concentrations were measured as in Fig. 1. Values are means \pm SEM for 4-10 rats per group. ${ }^{*} P<0.01$ vs. control value. 

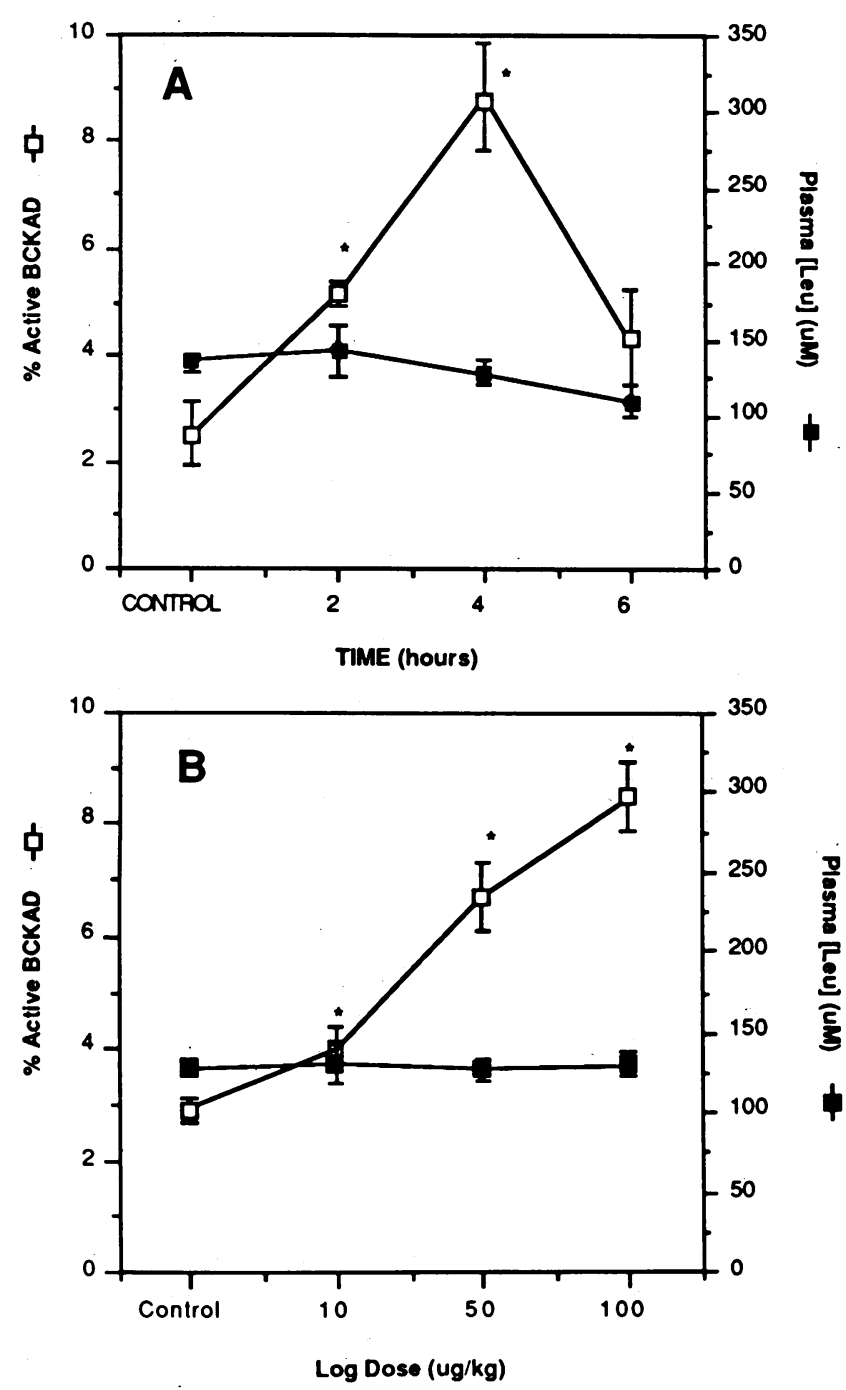

Figure 6. Effect of tumor necrosis factor administration on muscle BCKAD activity and plasma leucine concentrations. $(A)$ TNF $(50$ $\mu \mathrm{g} / \mathrm{kg}$ i..v.) was administered and rats killed 2,4 , and $6 \mathrm{~h}$ later. Controls received an equal volume of PBS containing albumin. Muscle BCKAD activity and plasma leucine were measured as in Fig. 1. Values are means \pm SEM for four to six rats per group. ${ }^{*} P<0.01$ vs. control value. $(B)$ Increasing doses of TNF were administered intravenously and rats killed $4 \mathrm{~h}$ later. Controls received PBS containing albumin. Muscle BCKAD activity and plasma leucine concentrations were measured as in $A$. Values are means \pm SEM for $6-13$ rats per group. ${ }^{*} P<0.01$ vs. control value.

after intravenous injections of saline, TNF $(10,50$, or 100 $\mu \mathrm{g} / \mathrm{kg}$ ) or endotoxin $(5-10 \mathrm{mg} / \mathrm{kg}$ ) (Table II). With each dose of TNF tested ( $n=6-8 /$ group) most amino acid concentrations in muscle were slightly higher in the treated rats than in controls, but the differences were not significant. When all TNF-treated rats were analyzed as one group regardless of dose $(n=20)$ and compared to controls $(n=16)$, only the concentration of phenylalanine was found to be significantly increased $(\sim 30 \%, P<0.05)$ in the treated group. The plasma phenylalanine concentrations were essentially identical in the two groups $(55 \pm 3 \mu \mathrm{M}$ in controls and $58 \pm 2 \mu \mathrm{M}$ in TNF treated), as were those of the plasma BCAA (Table I and Fig. 6 ). In contrast, treatment with endotoxin caused significant increases in the concentrations of BCAA, and phenylalanine in muscle $(P<0.05)$; the increase in valine was significant only when the treated rats were compared to the concurrently assayed controls $(n=5, P<0.05)$. The data in Table II relates amino acid concentrations to tissue weight; since endotoxin increased the concentrations of BCAA and phenylalanine in plasma, the intracellular concentrations of amino acids were also calculated as previously described (20), assuming that the ratio of intra- and extracellular water to muscle weight was not altered by the experimental treatments and that extracellular water was at equilibrium with plasma. The endotoxin induced increases in calculated intracellular leucine, valine, and phenylalanine were significant $(P<0.02$ compared to controls in the same experiment, $n=5 /$ group) but isoleucine was not (data not shown). The endotoxin effects on amino acid concentrations in skeletal muscle shown are similar to those reported in septic rats (42).

\section{Discussion}

The data presented demonstrate that endotoxin causes dose dependent activation of skeletal muscle BCKAD within $4 \mathrm{~h}$ after intravenous injection. In contrast to liver, skeletal muscle BCAA transaminase is abundant while the second enzyme of BCAA catabolism, BCKAD, is largely in the inactive form in the postabsorptive state (17). Therefore, in this tissue BCKAD is considered rate-limiting for BCAA catabolism. This does not rule out the possibility that mitochondrial BCKA transport may be rate-limiting under certain conditions (43). In view of its mass, ( $\sim 40 \%$ of body wt) skeletal muscle contributes significantly to BCAA oxidation by the organism (17). Although the actual contribution of muscle to total body BCAA oxidation has not been determined, studies with perfused hindquarters (reviewed in 17, 44) suggest that a $10 \%$ contribution in normal, chow-fed rats, at rest; in the postabsorptive state may be a conservative estimate. Hence, the three- to fourfold activation of BCKAD observed after endotoxin treatment, may account for, or at least contribute to the accelerated oxidation of BCAA observed with septicemia. While the increased concentrations of circulating glucocorticoids associated with sepsis (45) may contribute to BCKAD activation (20), our data indicate that endotoxin-induced muscle BCKAD activation is not mediated by stimulation of glucocorticoid secretion, since it also occurs in adrenalectomized rats receiving a single, minimally activating dose of MP (Fig. 4).

The fact that pretreatment of rats for $2 \mathrm{~d}$ with relatively high doses of cortisone prevented the activation of muscle BCKAD after endotoxin injection is consistent with the hypothesis that endotoxin-induced BCKAD activation is mediated by cytokines. Glucocorticoid treatment is known to prevent or blunt the response of macrophages to endotoxin, i.e., the synthesis and release of TNF (41), IL-1 (46) and that of histamine (47). Indeed, injection of rats with either TNF or IL- 1 activated muscle BCKAD to a similar degree as endotoxin administration, although TNF activated the complex more rapidly than the other treatments. The reason for the difference in plasma amino acid profiles between rats treated with endotoxin $(1-10 \mathrm{mg} / \mathrm{kg})$ and cytokines is not clear. In postabsorptive rats, circulating BCAA presumably increase when the rate of net protein catabolism exceeds the rate of BCAA oxidation. The observed differences may reflect the release of other unidentified cytokines in response to endotoxin which promote net protein catabolism $(33,34)$ and/or differences in the mode of administration (i.e., single bolus 
Table II. Effects of Endotoxin and TNF on Amino Acid Concentrations in Muscle

\begin{tabular}{|c|c|c|c|c|c|c|}
\hline Treatment & Dose & $n$ & Leu & Ile & Val & Phe \\
\hline & $\begin{array}{l}\mu \mathrm{g} / \mathrm{kg} \text { for } T N F \text { and } \\
\mathrm{mg} / \mathrm{kg} \text { for endotoxin }\end{array}$ & & \multicolumn{4}{|c|}{ nmol/g muscle } \\
\hline Saline & & 16 & $85 \pm 7$ & $58 \pm 4$ & $218 \pm 22$ & $64 \pm 5$ \\
\hline TNF & 10 & 6 & $99 \pm 7$ & $70 \pm 5$ & $263 \pm 49$ & $79 \pm 8$ \\
\hline TNF & 50 & 6 & $91 \pm 18$ & $58 \pm 10$ & $255 \pm 38$ & $96 \pm 21$ \\
\hline TNF & 100 & 8 & $94 \pm 12$ & $61 \pm 7$ & $268 \pm 24$ & $84 \pm 9$ \\
\hline All TNF treated & $10-100$ & 20 & $96 \pm 7$ & $63 \pm 4$ & $262 \pm 21$ & $86 \pm 7^{*}$ \\
\hline Endotoxin & $5-10$ & 5 & $163 \pm 16^{*}$ & $80 \pm 8^{*}$ & $262 \pm 22$ & $106 \pm 11^{*}$ \\
\hline
\end{tabular}

Saline injected controls were studied concurrently with experimentals and data are pooled. TNF data are from studies shown in Fig. 6 B. Endotoxin studies are from a separate experiment. All rats were killed $4 \mathrm{~h}$ after injections, muscles were frozen, and amino acid concentrations in homogenates measured, after deproteinization with $5 \%$ sulfosalicylic acid, as described (37). ${ }^{*} P<0.05$ compared with control values.

injection vs. endogenous production of cytokines) and/or synergistic effects of various endogenously released cytokines, i.e., TNF and IL-1 (31). Note, that a low dose $(0.25 \mathrm{mg} / \mathrm{kg})$ endotoxin acted like the cytokines, i.e., BCKAD, was activated without a concomitant increase in plasma BCAA or phenylalanine.

While there is an extensive and rapidly growing literature concerning the effects of IL- 1 and TNF on a number of organ systems and cell lines, there is surprisingly little information concerning their effects on skeletal muscle metabolism or on amino acid metabolism in general. TNF causes rapid depolarization of rat skeletal muscle in vitro, with maximal effects at $10^{-9} \mathrm{M}$ (48). In vitro, TNF or IL-1 did not affect lactate or alanine release, by rat diaphragms within $2 \mathrm{~h}$, although glucose oxidation was mildly stimulated (49). Marked acceleration of glucose transport, glucose transporter synthesis, lactate production and glycogenolysis was observed in a muscle derived cell line (L-6 myotubes) upon exposure to TNF, but not IL-1 (50).

The effects of these cytokines on muscle protein turnover is controversial. Two laboratories $(33,35)$ failed to detect an effect of recombinant IL-1, TNF, or a number of other identified macrophage products on protein degradation or synthesis by isolated rat skeletal muscles during 2 -h incubations. Furthermore, muscles removed from rats 4 to $24 \mathrm{~h}$ after injections of IL-1 or TNF showed no evidence of accelerated net protein degradation in vitro (34). The cytokine doses administered (34) were 2-80-fold greater than those that caused maximal BCKAD activation after intravenous bolus injection in our study. Since crude IL-1, prepared from media conditioned by endotoxin stimulated macrophages $(33,35)$ or serum from infected cattle (33) stimulated muscle protein degradation in vitro, a yet unidentified cytokine(s) was suggested to mediate the protein catabolic effects of septicemia. $6 \mathrm{~h}$ infusions of recombinant rat $\mathrm{IL}-1$, at much lower doses than those used here, did not affect either muscle protein turnover or whole body leucine oxidation (36). Recently, Flores et al. (31) reported accelerated muscle protein degradation in rats infused for $6 \mathrm{~h}$ with TNF or IL-1 with doses (one-half as the initial bolus) similar to those used here. Based on in vivo measurements of $\left[1-{ }^{14} \mathrm{C}\right]$ leucine kinetics, they also observed an increase in the percent leucine oxidized in rats treated with $100 \mu \mathrm{g} / \mathrm{kg}$ TNF. Although no increase in total body leucine oxidation was observed, this may be a reflection of the kinetic model used; calculations were based on the specific radioactivity of leucine in plasma whereas the muscle/plasma ratio of leucine specific radioactivity declined during cytokine infusions (31).

The apparent increase in muscle phenylalanine in TNF treated rats observed here, is consistent with the report (31) that TNF accelerates net muscle protein degradation, because phenylalanine is not synthesized or degraded by muscle; however, an effect on transport cannot be ruled out. The lack of a significant concomitant increase in muscle BCAA may reflect the accelerated oxidation of the BCAA in situ. In a number of conditions, i.e., uncompensated insulinopenic diabetes (51), glucocorticoid excess (20) and chronic acidosis (52) accelerated net protein degradation is associated with activation of muscle BCKAD and with accelerated BCAA oxidation by muscle. While in many protein catabolic conditions circulating and muscle BCAA concentrations are increased $(7,18,20$, $51)$ they are decreased in chronic metabolic acidosis (52). BCAA and specially leucine have been suggested to inhibit protein degradation and to stimulate muscle protein synthesis (reviewed in 53). If activation of muscle BCKAD can be equated with accelerated flux of leucine through the oxidative pathway (there have been no reports so far where this did not occur), then conceivably decreased leucine in a critical, intracellular pool may contribute to net protein degradation.

IL-1 and TNF have no structural homology and bind to separate receptors (54), some of their biological actions are not shared (reviewed in 22). At much higher doses than those used here $(0.6-4 \mathrm{mg} / \mathrm{kg}$ i.v.) TNF elicits the systemic effects characteristic of endotoxin shock in rats, i.e., hypotension, hypoglycemia, lactic acidosis, and death $(55,56)$. The strongest argument supporting a role for TNF in septic shock is derived from the findings that $(a)$ circulating TNF increases markedly within $2 \mathrm{~h}$ after LPS injection and $(b)$ pretreatment of mice or rabbits with anti-TNF antibody prevents systemic effects and death caused by lethal doses of $\operatorname{LPS}(25,26)$.

As discussed in Methods, the TNF doses that activated muscle BCKAD likely resulted in serum TNF concentrations that occur in vivo early in the course of gram negative infections (26). Exposure to endotoxin elicits TNF secretion by macrophages, which then become refractory, i.e., subsequent endotoxin exposure does not elicit TNF secretion $(23,26)$. This may explain why increased circulating TNF is not consistently observed in septic patients (57-59). The half life of TNF in the circulation is very short, $<15 \mathrm{~min}$, and it is preferentially taken up by tissues other than muscle (60). Various interactions between cytokines have been reported, which in- 
clude TNF and IL-1 stimulation of the synthesis and/or release of other mediators or cytokines or of each other $(22,61,62)$. The similarity of the responses to IL-1 and TNF in our experiments and the lack of a significant additive effect suggest that muscle BCKAD activation induced by the two cytokines was either mediated by a factor(s) released in response to both cytokines, or one cytokine induced secretion of the other (22), or if they acted via separate receptors on muscle cells, these induce BCKAD activation through a shared common pathway.

Since BCKAD activation by each of the agents tested in our experiments occurred within $4 \mathrm{~h}$ after intravenous injection, and since IL-1 and TNF are known to exert many of their effects by modifying gene expression, $(23,24,32,50,54,62)$, an attractive hypothesis for the observed BCKAD activation by TNF and IL-1 would entail transcriptional regulation of BCKAD-kinase or BCKAD-phosphatase or that of their proposed modulator proteins $(16,17)$. KIC is a potent inhibitor of BCKAD-kinase, and in many conditions, muscle BCKAD activation correlates with plasma and intracellular concentrations of leucine (19-21). However muscle BCKAD activation has been observed without concomitant increases in leucine, i.e., after the co-injection of $\alpha$-methylprednisolone and insulin (20) in chronic acidosis (52), or after exercise (63). The intramitochondrial concentration of KIC, which affects BCKAD activation, reflects the intracellular leucine and KIC concentrations as well as the activity of the mitochondrial transport system for branched chain $\alpha$-keto acids, which in turn is modulated by $\Delta \mathrm{pH}(43)$. Increased lactate production $(50,55)$ may lower the cytosolic $\mathrm{pH}$ in muscle resulting in increased $\Delta \mathrm{pH}$, accumulation of intramitochondrial $\mathrm{KIC}$, and BCKAD activation. Reduction in the intramitochondrial $A T P / A D P$ ratio could also contribute to BCKAD activation (63). Further studies of the actual mechanism(s) by which cytokines and endotoxin activate BCKAD complex seem warranted; they may be relevant to proposed nutritional therapy of septic patients (64) and to the ongoing investigations of the use of cytokines in cancer therapy $(65,66)$.

\section{Acknowledgments}

We thank Drs. Claudine Ferland, Neil Farber, and Alan R. Shaw, Biogen Research Corp., Cambridge, MA for generous gifts of TNF- $\alpha$ and IL- $1 \alpha$ and $\beta$, Ms. Sandra Dutton for technical assistance in some experiments, and Ms. Barbara Whitlock and Ms. Debra Riebe for expert secretarial assistance.

This investigation was supported by Grant AM-02001 from the National Institute of Diabetes, Digestive and Kidney Diseases, U.S. Public Health Service.

\section{References}

1. Cerra, F. B. 1983. Influence of nutrition on the outcome of septic patients. In: New Aspects of Clinical Nutrition. G. Kleinberger and E. Deutsch, editors. Karger, Basel, 136-145.

2. Beisel, W. R., and R. W. Wannemacher. 1980. Gluconeogenesis, ureagenesis, and ketogenesis during sepsis. J. Parenter. Enteral Nutr. 4:277-285.

3. Rosenblatt, S., G. H. A. Clowes, B. C. George, E. Hirsch, and B. Lindberg. 1983. Exchange of amino acids by muscle and liver in sepsis. Arch. Surg. 118:167-175.

4. Loda, M., G. H. A. Clowes, C. A. Dinarello, B. C. George, B. Lane, and W. Richardson. 1984. Induction of hepatic protein synthesis by a peptide in blood plasma of patients with sepsis and trauma. Surgery (St. Louis). 96:204-213.
5. Ryan, N. T., G. L. Blackburn, and G. H. Clowes. 1974. Differential tissue sensitivity of elevated endogenous insulin levels during experimental peritonitis in rats. Metab. Clin. Exp. 23:1081-1089.

6. O'Donnell, T. F., G. H. A. Clowes, G. L. Blackburn, T. Ryan, P. N. Benotti and J. D. B. Miller. 1976. Proteolysis associated with a deficit of peripheral energy fuel substrates in septic man. Surgery (St. Louis). 80:192-200.

7. Wannemacher, R. W. 1977. Key role of various individual amino acids in host response to infection. Am. J. Clin. Nutr. 30:12691280 .

8. Clowes, G. H. A., H. T. Randall, and C.-J. Cha. 1980. Amino acid and energy metabolism in septic and traumatized patients. $J$. Parenter. Enteral Nutr. 4:195-205.

9. Cerra, F. B., J. H. Siegel, and B. Coleman. 1980. Septic autocannibalism: a failure of exogenous nutritional support. Ann. Surg. 192:570-574

10. Moyer, E. D., R. H. McMenamy, F. B. Cerra, R. A. Reed, B. A. L. Yu, R. Chenier, J. Carvana, and J. R. Border. 1981. Multiple systems organ failure: III. Contents in plasma amino acid profiles in septic trauma patients who subsequently survive and do not surviveeffects of intravenous amino acids. J. Trauma. 21:263-274.

11. Pomposelli, J. J., J. D. Palombo, K. J. Hamawy, B. R. Bistrian, G. L. Blackburn and L. L. Moldawer. 1985. Comparison of different techniques for estimating rates of protein synthesis in vivo in healthy and bacteraemic rats. Biochem. J. 226:37-42.

12. Woolf, L. I., A. C. Groves, and J. H. Duff. 1979. Amino acid metabolism in dogs with E. coli bacteremic shock. Surgery (St. Louis). 85:212-218.

13. Groves, A. C., L. I. Woolf, J. H. Duff, and R. J. Finley. 1983. Metabolism of branched-chain amino acids in dogs with Escherichia coli endotoxin shock. Surgery (St. Louis). 93:273-278.

14. Duff, J. H., T. Viidik, J. B. Marchuk, R. L. Holliday, R. J. Finley, A. C. Groves, and L. I. Woolf. 1979. Femoral arteriovenous amino acid differences in septic patients. Surgery (St. Louis). 85:344 348.

15. Ryan, N. T. 1976. Metabolic adaptations for energy production during trauma and sepsis. Surg. Clin. N. Am. 56:1073-1090.

16. Randle, P. J., H. R. Fatania, and K. S. Lau. 1984. Regulation of the mitochondrial branched-chain 2-oxoacid dehydrogenase complex of animal tissues by reversible phosphorylation. Mol. Aspects Cell. Regul. 3:1-26.

17. Harper, A. E., R. H. Miller, and K. P. Block. 1984. Branchedchain amino acid metabolism. Annu. Rev. Nutr. 4:409-454.

18. Vary, T., J. H. Siegel, T. Nakatani, T. Sato, and H. Aoyama. 1986. Effect of sepsis on activity of pyruvate dehydrogenase complex in skeletal muscle and liver. Am. J. Physiol. 250:E634-E640.

19. Aftring, R. P., K. P. Block, and M. G. Buse. 1986. Leucine and isoleucine activate skeletal muscle branched-chain $\alpha$-keto acid dehydrogenase in vivo. Am. J. Physiol. 250:E599-E604.

20. Block, K. P., W. B. Richmond, W. B. Mehard, and M. G. Buse. 1987. Glucocorticoid-mediated activation of muscle branched-chain $\alpha$-keto acid dehydrogenase in vivo. Am. J. Physiol. 252:E396-E407.

21. Block, K. P., R. P. Aftring, W. G. Mehard, and M. G. Buse. 1987. Modulation of rat skeletal muscle branched-chain $\alpha$-keto acid dehydrogenase in vivo: Effects of dietary protein and meal consumption. J. Clin. Invest. 79:1349-1358.

22. Nathan, C. F. 1987. Secretory products of macrophages. $J$. Clin. Invest. 79:319-326.

23. Beutler, B., J. Mahoney, N. LeTrang, P. Pekala, and A. Cerami. 1985. Purification of cachectin, a lipoprotein lipase-suppressing hormone secreted by endotoxin-induced RAW 264.6 cells. J. Exp. Med. 161:984-995.

24. Moldawer, L. L., S. F. Lowry, and A. Cerami. 1988. Cachectin: its impact on metabolism and nutritional status. Annu. Rev. Nutr. 8:585-609.

25. Beutler, B., I. W. Milsark, and A. C. Cerami. 1985. Passive immunization against cachectin/tumor necrosis factor protects mice from lethal effects of endotoxin. Science (Wash. DC). 229:869-871.

26. Mathison, J. C., E. Wolfson, and R. J. Ulevitch. 1988. Partici- 
pation of tumor necrosis factor in the mediation of gram negative bacterial lipopolysaccharide-induced injury in rabbits. J. Clin. Invest. 81:1925-1937.

27. Baracos, V. E., H. P. Rodemann, C. A. Dinarello, and A. L. Goldberg. 1983. Stimulation of muscle protein degradation and prostaglandin $\mathrm{E}_{2}$ release by leukocytic pyrogen (interleukin-1). N. Engl. J. Med. 308:553-558.

28. Goldberg, A. L., V. Baracos, P. Rodemann, L. Waxman, and C. Dinarello. 1984. Control of protein degradation in muscle by prostaglandins, $\mathrm{Ca}^{2+}$, and leukocytic pyrogen (interleukin-1). Fed. Proc. 43:1301-1306.

29. Pomposelli, J. J., E. A. Flores, and B. R. Bistrian. 1988. The role of biochemical mediators in clinical nutrition and surgical metabolism. J. Parenter. Enteral Nutr. 12:212-218.

30. Warren, R. S., H. F. Starnes, J. L. Gabrilove, H. F. Oettgen, and M. F. Brennan. 1987. The acute metabolic effects of tumor necrosis factor administration. Arch. Surg. 122:1396-1400.

31. Flores, E. A., B. R. Bistrian, J. J. Pomposelli, C. A. Dinarello, G. L. Blackburn, and N. W. Istfan. 1989. Infusion of tumor necrosis factor/cachectin promotes muscle catabolism in the rat. A synergistic effect with interleukin 1. J. Clin. Invest. 83:1614-1622.

32. Tracy, K. J., S. F. Lowry, and A. Cerami. 1988. Cachectin: A hormone that triggers acute shock and chronic cachexia. J. Infect. Dis. 157:413-420.

33. Goldberg, A. L., I. C. Kettelhut, K. Furuno, J. M. Fagan, and V. Baracos. 1988. Activation of protein breakdown and prostaglandin $E_{2}$ production in rat skeletal muscle in fever is signaled by a macrophage product distinct from interleukin 1 or other known monokines. $J$. Clin. Invest. 81:1378-1383.

34. Kettelhut, I. C., and A. L. Goldberg. 1988. Tumor necrosis factor can induce fever in rats without activating protein breakdown in muscle or lipolysis in adipose tissue. J. Clin. Invest. 81:1384-1389.

35. Moldawer, L. L., G. Svaninger, J. Gelin, and K. G. Lundholm. 1987. Interleukin 1 and tumor necrosis factor do not regulate protein balance in skeletal muscle. Am. J. Physiol. 253:C766-C773.

36. Tocco-Bradley, R., L. L. Moldawer, C. T. Jones, B. Gerson, G. L. Blackburn, and B. R. Bistrian. 1986. The biological activity in vivo of recombinant murine interleukin 1 in the rat. Proc. Soc. Exp. Biol. Med. 182:263-271.

37. Aftring, R. P., P. N. Manos, and M. G. Buse. 1985. Catabolism of branched-chain amino acids by diaphragm muscles of fasted and diabetic rats. Metab. Clin. Exp. 34:702-711.

38. Steel, R. G. D., and J. H. Torrie. 1960. Principles and procedures of statistics. McGraw-Hill Book Co., New York. 157.

39. Harper, J. F. 1984. Pertiz's F test: basic program of robust multiple comparison test for statistical analyses of all differences among group means. Comput. Biol. Med. 14:437-445.

40. Jepson, M., M. Pell, P. C. Bates, and D. J. Millward. 1986. Effects of endotoxemia on protein metabolism in skeletal muscle and liver of fed and fasted rats. Biochem. J. 235:329-336.

41. Beutler, B., N. Krochin, I. W. Milsark, C. Luedke, and A. Cerami. 1986. Control of cachectin (tumor necrosis factor) synthesis: mechanisms of endotoxin resistance. Science (Wash. DC). 232:977980.

42. Vary, T. C., J. H. Siegel, A. Zechnich, B. D. Tall, J. G. Morris, R. Placko, and D. Jawor. 1988. Pharmacological reversal of abnormal glucose regulation, BCAA utilization and muscle catabolism in sepsis by dichloroacetate. J. Trauma. 28:1301-1311.

43. Hutson, S. M. 1986. Branched-chain $\alpha$-keto acid oxidative decarboxylation in skeletal muscle mitochondria. Effect of isolation procedure and mitochondrial $\Delta$ pH. J. Biol. Chem. 261:4420-4425.

44. Hood, D. A., and Terjung, R. L. 1987. Leucine metabolism in perfused rat skeletal muscle during contractions. Am. J. Physiol. 253:E636-E647.

45. Kinney, J. M., and P. Felig. 1979. The metabolic response to injury and infection. In Endocrinology. Vol. 3. L. J. DeGroot, editor. Grune \& Stratton, Inc., New York. 1963-1985.

46. Dinarello, C. A. 1984. Interleukin-1 and the pathogenesis of the acute-phase response. $N$. Engl. J. Med. 311:1413-1418.
47. Kogure, K., M. Ishizaki, M. Nemoto, T. Nakamura, and M. Suzuki. 1986. Antishock effects of corticosterone on dextran-induced shock in rats. Am. J. Physiol. E569-E575.

48. Tracey, K. J., S. F. Lowry, B. Beutler, A. Cerami, J. D. Albert, and G. T. Shires. 1986. Cachectin/tumor necrosis factor mediates changes of skeletal muscle plasma membrane potential. J. Exp. Med. 164:1368-1373.

49. Rofe, A. M., R. A. J. Conyers, R. Bais, J. R. Gamble, and M. A. Vadas. 1987. The effects of recombinant tumour necrosis factor (cachectin) on metabolism in isolated rat adipocyte, hepatocyte and muscle preparations. Biochem. J. 247:789-792.

50. Lee, M. D., A. Zentella, P. H. Pekala, and A. Cerami. 1987. Effect of endotoxin-induced monokines on glucose metabolism in the muscle cell line L6. Proc. Natl. Acad. Sci. USA. 84:2590-2594.

51. Aftring, R. P., W. J. Miller, and M. G. Buse. 1988. Effects of diabetes and starvation on skeletal muscle branched-chain $\alpha$-keto acid dehydrogenase activity. Am. J. Physiol. 254:E292-E300.

52. May, R. C., Y. Hara, R. A. Kelly, K. P. Block, M. G. Buse, and W. E. Mitch. 1987. Branched-chain amino acid metabolism in rat muscle: abnormal regulation in acidosis. Am. J. Physiol. 252:E712E718.

53. May, M. E., and M. G. Buse. 1989. Effects of branched chain amino acids on protein turnover. Diabetes Metab. Rev. 5:227-245.

54. Beutler, B. A., and A. Cerami. 1985. Recombinant interleukin 1 suppresses lipoprotein lipase activity in 3T3-L1 cells. J. Immunol. 135:3969-3971.

55. Kettelhut, I. C., W. Fiers, and A. L. Goldberg. 1987. The toxic effects of tumor necrosis factor in vivo and their prevention by cyclooxygenase inhibitors. Proc. Natl. Acad. Sci. USA. 84:4273-4277.

56. Tracey, K. M., B. Beutler, S. F. Lowry, J. Merryweather, S. Wolpe, I. W. Milsark, R. J. Hariri, T. J. Fahey, A. Zentella, J. D. Albert, T. Shires, and A. Cerami. 1986. Shock and tissue injury induced by recombinant human cachectin. Science (Wash. DC). 234:470-474.

57. Waage, A., T. Espevik, and A. Halstensen. 1987. Association between tumour necrosis factor in serum and fatal outcome in patients with meningococcal disease. Lancet. i:355-357.

58. Ziegler, E. J. 1988. Tumor necrosis factor in humans. N. Engl. J. Med. 318:1533-1535.

59. Michie, H. R., K. R. Manogue, D. R. Spriggs, A. Revhaug, S. O'Dwyer, C. A. Dinarello, A. Cerami, S. M. Wolff, and D. W. Wilmore. 1988. Detection of circulating tumor necrosis factor after endotoxin administration. N. Engl. J. Med. 318:1481-1486.

60. Beutler, B. A., I. W. Milsark, and A. Cerami. 1985. Cachectin/ tumor necrosis factor: Production, distribution, and metabolic fate in vivo. J. Immunol. 135:3972-3977.

61. Sun, X.-M., and W. Hsueh. 1988. Bowel necrosis induced by tumor necrosis factor in rats is mediated by platelet-activating factor. $J$. Clin. Invest. 81:1328-1331.

62. Seelentag, W. K., J.-J. Mermod, R. Montesano, and P. Vassalli. 1987. Additive effects of interleukin 1 and tumour necrosis factor- $\alpha$ on the accumulation of the three granulocyte and macrophage colonystimulating factor mRNA in human endothelial cells. EMBO (Eur. Mol. Biol. Organ.) J. 6:2261-2265.

63. Kasparek, G. J., G. L. Dohm, and R. D. Snider. 1985. Activation of branched-chain $\alpha$-keto acid dehydrogenase by exercise. Am. J. Physiol. 248:R166-R171.

64. Brennan, M. F., F. Cerra, J. M. Daly, J. E. Fischer, L. L. Moldawer, R. J. Smith, E. Vinnars, R. Wannemacher, and V. R. Young. 1986. Report of a research workshop: branched-chain amino acids in stress and injury. J. Parenter. Enteral Nutr. 10:446-452.

65. Spriggs, D. R., M. L. Sherman, E. Frei III, and D. W. Kufe. 1987. Clinical studies with tumor necrosis factor. Tumor necrosis factor and related cytotoxins. Ciba Found. Symp. 131:219-227.

66. Starnes, M. F., Jr., R. S. Warren, M. Jeevanandam, J. L. Gabrilove, W. Larchian, N. F. Oettgen, and M. F. Brennan. 1988. Tumor necrosis factor and acute metabolic injury in man. J. Clin. Invest. 82:1321-1325. 